\title{
Resistance to set breaking as a function of frustrative error making*
}

\author{
RONALD R. SCHMECK, Southern Mlinois University, Carbondale, Ill. 62901 \\ and \\ PAUL CLEMENTS, Ilinois Institute of Technology, Chicago, Ill. 60616
}

As part of a research project concerned with the involvement of error-produced frustration in the performance of complex tasks, the present studies investigated the possibility that errors preceding the acquisition of a correct response can increase the probability of occurrence of that response. Such an effect would presumably be due either to the reinforcement produced by the reduction in error-produced frustration which accompanies the performance of the correct response or to the frustration-produced suppression of all aiternative responses. The number of errors preceding the acquisition of a "set" solution to a task was manipulated by initially confronting the $S$ with unsolvable items. It was found that a "set response" which was preceded by numerous unsolvable items was more resistant to "set breaking" than one preceded by no unsolvable items.

Schmeck \& Bruning (1968) demonstrated that frustrative nonreward preceding the performance of a complex task increased the error rate of Ss on that task. Subsequently, Schmeck (1970) both manipulated and measured error rate on a complex task and found that measured error rate increased as a function of increases in manipulated error rate. It was suggested that the latter effect could be attributed to the influence of the frustration produced by the errors themselves. The experiments described below were designed to test a further implication of the assumption that errors produce frustration.

It had been noted by Schmeck \& Bruning (1970) that, if errors are indeed frustrating, then having a correct response on a particular task preceded by several errors could produce one or both of two effects. First, if the correct response which follows a series of errors reduces the frustration-produced drive resulting from those errors, then that response might develop exceptionally high habit strength. Second, the contiguity of the response-produced cues associated with the errors and the frustration reactions produced by the errors should lead to a reduction in the strengths of those responses (extinction). In either case, the probability of occurrence of the correct response should be increased.

The current studies employed a set-breaking approach similar to that used by Maltzman \& Morrisett (1952). In the present experiments, a high number of errors was produced early in training by making the initial training items logically unsolvable. These items were followed by solvable

* This research was supported by Southern Illinois University Research and Projects Grant 05-15-62. set-inducing items and finally by test items that were solvable by a method simpler than the set method. It was assumed that greater resistance to set breaking would be an indication either that the correct response had acquired greater habit strength or that all alternative responses had been suppressed, with either effect attributable to the initial frustrating experience.

\section{EXPERIMENT I}

Subjects and Apparatus

Forty volunteer undergraduate students from the introductory psychology course at Southern Illinois University were employed as Ss. The Ss were assigned randomly to one of two groups of 20 .

The basic task employed in this first experiment was described by Schmeck \& Ribich (1969). Briefly, it was a seven-letter hidden-word task composed of 40 items. All Ss were instructed to find, in each of the groups of letters, a hidden four-letter word without transposing the order of the letters. The set method consisted of choosing every other letter, beginning with the first. The nonset method simply involved choosing four consecutive letters that already formed a word. The items were typed in capital letters (five items to a page) and presented to the $S$ s in booklet form. The Ss indicated their choice of letters by filling in a circle below each letter. For the nonfrustrated group, the first 20 items could be solved only by the set method, while the last 20 items could be solved by either the set or the nonset method. The frustrated group received 10 items that were logically impossible to solve, followed by 10 items solvable by the set method, followed by 20 items solvable by either method. Items 11-40 were the same for both groups. All Ss were instructed not to proceed to later items before attempting to solve each of the previous items.

Two things should be noted at this point. First, the total numbers of items given to each group were equated. Second, the initial 10 items given to the nonfrustrated group were made set-inducing rather than solvable by some alternative method. This was done in order to ensure that any effect due to a difference in number of set-training trials (as in the study conducted by Maltzman \& Morrisett, 1952) would favor the nonfrustrated group rather than the frustrated group. If the initial 10 items given to the nonfrustrated Ss had been solvable by some alternative method, then behavioral variability might have been "trained into" those Ss. In this manner, the first study provided a conservative test of the prediction that frustrated Ss would demonstrate more persistence in the use of the set solution than would nonfrustrated Ss. Results and Discussion

In order to ensure that the set response had developed a minimal amount of habit strength in both groups, the criterion employed was that all Ss who did not use the set method at least once during the test trials were discarded. Whether a $S$ was retained or discarded was apparently independent of the treatment conditions, since equal numbers of $\mathrm{Ss}$ were discarded from the two groups.

With 16 Ss remaining in each group, the results indicated that, during the 20 test trials, the frustrated group used the set method significantly more often ( $\bar{X}=8.03 ; S D=3.78)$ than the nonfrustrated group $(\bar{X}=3.52$; $\mathrm{SD}=3.34) \quad[\mathrm{t}(30)=3.57, \quad \mathrm{p}<.01]$ Theoretically, either the frustration reduction produced by the set response, following the 10 unsolvable, frustrating items, or the suppression of alternative responses during the 10 initial items produced the additional increment in the probability of occurrence of the set response.

\section{EXPERIMENT II}

The second experiment was an attempt to replicate the first experiment using an apparatus and a procedure which permitted a greater amount of experimental control. The task was simplified, and the items were presented on a memory drum to individual Ss.

Subjects and Apparatus

The second experiment employed 36 volunteer Ss from the introductory psychology courses at Southern nlinois University. The Ss were divided randomly into two groups of 18 . The task consisted of 28 three-letter items. The set-inducing items required the $\mathbf{S}$ to read the three letters in reverse order, e.g., EHT was responded to 
Table 1

Mean Number of Set Responses Demonstrated on Those Items that Were Solvable by Either the Set Method or a Simpler Method

Early vs Late Test Trials

\begin{tabular}{|c|c|c|c|c|}
\hline \multirow{4}{*}{$\begin{array}{l}\text { Treatment } \\
\text { Frustration } \\
\text { Nonfrustration }\end{array}$} & & & & \\
\hline & \multicolumn{2}{|c|}{ First Five Test Trials } & \multicolumn{2}{|c|}{ Last Five Test Trials } \\
\hline & 4.44 & $(\mathrm{SD}=1.29)$ & 2.72 & $(S D=1.90)$ \\
\hline & 2.72 & $(\mathrm{SD}=1.96)$ & 1.39 & $(S D=1.82)$ \\
\hline
\end{tabular}

with "the." The test items consisted of three letters which formed a word when spelled either forward or backward, e.g., BUT is responded to with either "tub" or "but." The items were presented to each $\mathrm{S}$ on a memory drum using an 8-sec presentation interval.

Procedure

The frustrated Ss received 5 unsolvable items, followed by 9 set-inducing items, followed by 10 test items which were interspersed with 10 set items. The nonfrustrated $\mathrm{Ss}$ received 14 set-inducing items followed by the same mixed series of 10 test and 10 set items. The experiment was conducted in a sound-deadened room. They were told that "each group of three letters will be visable for only $8 \mathrm{sec}$. During that interval you are to find and state aloud a meaningful three-letter word that can be spelled with the three letters. If you do not find a word by the end of the $8 \mathrm{sec}$, concentrate on the next group of three letters that will be appearing in the window of the memory drum."

\section{RESULTS}

In order to examine the extent of use of the set solution early and late in the series of test problems, the data from this second experiment were divided into blocks composed of the first five and last five test trials. The mean numbers of set responses made during each test trial block by each of the two experimental groups are presented in Table 1.

Analysis of variance indicated that the overall effect of having training items preceded by unsolvable items was significant $[F(1,34)=7.85$, $p<.01]$. Frustrated Ss were quite resistant to set breaking. Likewise, the set response was used significantly more often early in the test series than it was during the later test trials $[F(1,34)=47.74, \quad p<.001]$. However, there was no indication that the effects of frustration were influenced by early vs late test trials $(\mathrm{F}<1.00)$.

These two studies support the analysis made by Schmeck \& Bruning (1970) of the influence of error-produced frustration on task performance. Schmeck (1970) demonstrated that such frustration can increase behavioral variability and, thus, produce an increase in the probability that additional errors will be made. The present studies indicate that errors preceding the correct response on a particular task can increase the probability of occurrence of that response. Whether this increased probability of occurrence is attributable to the reduction in error-produced frustration that accompanies a correct response or attributable to the frustrationproduced suppression of the alternative responses is still open to question.

The results of the present studies can be compared to those of Schmeck \& Ribich (1969). The latter authors reported that "rigidity" of performance was inversely related to task complexity. Since the present studies were concerned with set-breaking behavior similar to that of the Schmeck \& Ribich (1969) study, the results of the present studies might likewise be regarded as an indication of which factors reduce behavioral variability (i.e., produce "rigidity"). In the present case, "rigidity" appears to be a direct function of the number of frustrative errors that preceded successful task performance, i.e., when several unsolvable items preceded the acquisition of a set, the set was exceptionally resistant to set breaking.

\section{REFERENCES}

MALTZMAN, I., \& MORRISETT L Different strengths of set in the solution of anagrams. Journal of Experimental Psychology, 1952, 44, 242-246.

SCHM ECK, R, R. Error-produced frustration as a factor influencing the probability of occurrence of further errors. Journal of Experimental Psychology, 1970,86, 153-156.

SCHMECK, R. R., \& BRUNING, J. L. Task difficulty and the frustration effect. Journal of Experimental Psychology, $1968,78,516-520$.

SCHMECK, R. R., \& BRUNING, J. L. Frustration theory and quality of performance: Elicitation and elimination of competing responses. Psychological Reports, $1970,26,987 \cdot 994$.

SCHMECK, R. R., \& RIBICH, F. Rigidity as a function of task complexity. Psychonomic Science, 1969, 17, 323. 